\title{
In-brace correction of the Cobb angle with RSC-CAD CAM compared with 'hand made' from the original author
}

\author{
Manuel D Rigo*, Dino Gallo, Robert Dallmayer \\ From 7th International Conference on Conservative Management of Spinal Deformities \\ Montreal, Canada. 20-22 May 2010
}

\section{Introduction}

The purpose of the present study is the comparison of the in-brace correction in a group of patients with idiopathic scoliosis treated with 'CAD CAM' RSC brace and a control group of patients treated with a 'hand made' RSC brace (from the original author, Rigo).

\section{Background}

RSC braces built with informatics assistance (CAD CAM) have shown similar in-brace corrections than 'hand made' RSC; however this has never been compared in matched samples.

\section{Method}

Case control study. Source: Ortholutions database from 2008 to 2009. Inclusion criteria: Patients with idiopathic scoliosis, no previous treatment (brace), younger than 15 and Risser 3 or less. Case group: 41 patients ( 2 males and 39 females) treated with CAD CAM RSC brace full filed the inclusion criteria. Control group: all the 27 patients ( 1 male 26 females) treated with 'hand made' RSC brace that full filed the inclusion criteria as well. Mean age was not different in the case group 11.3 y (SD 1.9) compared with the control 11.8 y (SD 2.1). Risser sign was higher $(\mathrm{p}<0.005)$ in the case group 0.8 (SD 1) in comparison with the control group 0.2 (SD 0.6). The Cobb angle out-brace of the major curve was not significantly different in both groups (case= $35.2^{\circ}+13^{\circ}$; control $\left.=33^{\circ}+7.7^{\circ}\right)$. Minor curve was not different $\left(\right.$ case $=26.4^{\circ}+/-11.8^{\circ}$; control $\left.=28.8^{\circ}+/-7.2^{\circ}\right)$.

Institut Elena Salvá, Barcelona, Spain

Full list of author information is available at the end of the article

\section{Results}

The in-brace Cobb angle of the major curve was $18.6^{\circ}$ $+/-14.1^{\circ}$ in the case group and $16.4^{\circ}+/-9.9^{\circ}$ in the control (NS). Minor curve measured $15.5^{\circ}+/-12.9^{\circ}$ in the case group and $18.4^{\circ}+/-6.9^{\circ}$ in the control (NS). Inbrace correction of the major curve (case $52.6 \%$; control $53.7 \%$ ) and the minor curve (case 45.6\%; control 36.8\%) was not significantly different in both groups. Total inbrace correction (major and minor curve) was also the same in both groups (case 49.3\%; control 47.9\%).

\section{Discussion}

The results of this study show that the Cobb angle can be corrected in the same proportion by using a CAD CAM brace in comparison with a brace built on a positive plaster mould modified by the original author of the RSC brace (Rigo). The CAD CAM ortholutions system uses a highly complete library of moulds provided by the original author of the RSC brace. Brace model is selected from the library for each patient according to his/her curve pattern (Rigo Classification) and morphology by the author. Afterwards, the brace is built by Ortholutions using CAD CAM according to specific patient measurements and fitted by an experienced and specifically trained orthopaedic technician. Both, patient measurement and fitting, are essential parts of the process in order to reach a proper treatment quality. When the full protocol is followed the CAD CAM brace is as effective and safe in reducing the Cobb angle in brace in the major as well as in the minor curve. In this present

study, the CAD CAM RSC brace reduced even more the minor curve in comparison with the hand made, although difference was not statistically significant, most probably due to the sample size. However, in-brace angles of the major and minor curve were more 
balanced with the hand made brace. We interpret this as a sign of the special purpose of the original author to reach such an in-brace correction balance, when fitting, rather than real structural differences between the two methods.

\section{Conclusion}

The in-brace correction of the Cobb angle achieved with a CAD CAM RSC brace is as effective as that observed with a 'hand made' brace from the original author.

Published: 10 September 2010

doi:10.1186/1748-7161-5-S1-068

Cite this article as: Rigo et al:: In-brace correction of the Cobb angle with RSC-CAD CAM compared with 'hand made' from the original author. Scoliosis 2010 5(Suppl 1):O68.
Submit your next manuscript to BioMed Central and take full advantage of:

- Convenient online submission

- Thorough peer review

- No space constraints or color figure charges

- Immediate publication on acceptance

- Inclusion in PubMed, CAS, Scopus and Google Scholar

- Research which is freely available for redistribution

Submit your manuscript at www.biomedcentral.com/submit 